Videbaek, A. \& Mosbech, J. (1954) Aetiology of gastric carcinoma elucidated by study of 302 pedigrees. Acta Medica Scandinavica, 149, 137.
Woolf, C.M. (1956) Further study on familial aspects of carcinoma of stomach. American Journal of Human Genetics, 8, 102.

\title{
Subacute combined degeneration of the spinal cord in a vegan
}

\author{
H. N. MISRA \\ M.B., B.S.(Cal.), M.R.C.P.(U.K.)
}

\author{
J. M. FAllowfield \\ M.B., Ch.B.(Manchester)
}

Wythenshawe Hospital, Manchester

SUBACUTE combined degeneration of the spinal cord in nutritional vitamin $\mathbf{B}_{12}$ deficiency states, though a rare complication, has been reported several times (Badenoch, 1954; Wokes, 1956; Smith, 1962; Connor \& Pirola, 1963; Riley, 1966; Verjaal \& Timmermans, 1967), and its association with veganism (vegans are people who exclude all forms of animal products from their diet) has been duly stressed by Wokes (1956) and Smith (1962). Although vegans would appear to be highly vulnerable subjects for deficiency disease, in fact the incidence of manifest symptoms and signs due to vitamin $B_{12}$ deficiency is rare, even when the serum levels are well below the range found in pernicious anaemia (Smith, 1962). The reason for this anomaly is not clear, though Smith (1962) advanced the view that tobacco smoking in vitamin $\mathbf{B}_{\mathbf{1 2}}$ deficiency states plays a definite role in the genesis of neurological complications, and of his reported cases, the only two patients with subacute combined degeneration of the spinal cord were smokers.

We consider our patient unique in the sense that she was a vegan who was a non-smoker but nevertheless she developed subacute combined degeneration of the spinal cord.

\section{Case report}

Miss D. A., aged 62 years, was admitted to Wythenshawe Hospital on 6.10.69 under the care of Dr C. D. R. Pengelly for the investigation of unsteadiness of gait and stiffness of her lower limbs. Her symptoms had started gradually over a 3-year period with tingling of hands and feet. She had noticed that handling money was difficult because it felt like sandpaper. Subsequently her gait became progressively ataxic until she was house-bound. Eventually she had to hold on to furniture to remain upright. Ten days before admission she fell and sustained a left Colles' fracture. She dismissed this as a bruised wrist and sought no medical treatment. The consequent lack of mobility and pressure from her neighbours led to her admission to hospital.

There was no significant history of past illness. She had been a vegetarian since 1943 and for 5 years prior to admission she had been a vegan. She had been a non-smoker and teetotaller all her life.

On admission physical examination revealed no evidence of malnutrition and there was no pallor. Examination of the alimentary, cardiovascular and respiratory systems revealed no abnormality. BP $170 / 90 \mathrm{mmHg}$, routine urine examination normal. Examination of the nervous system was as follows: mentality normal; cranial nerves normal; there was no abnormality in the power, tone or reflexes in the arms; the lower limbs were slightly spastic, she could hardly stand on her feet and she was completely unable to walk without support; Romberg's sign was strongly positive; both ankle jerks were diminished; plantar responses on both sides were extensor; there was slight diminution of light-touch and pinprick sensation over feet and hands; vibration sense was completely absent up to the lower end of the sternum and joint sensation was grossly impaired in both lower limbs.

Investigations. $\mathrm{Hb} 10.5 \mathrm{~g} / 100 \mathrm{ml}, \mathrm{PCV} 34 \%$, MCHC $30 \%$, WCC $5000 / \mathrm{mm}^{3}$. Peripheral blood film: some macrocytes, normal differential count. RBC normochromic. Blood urea $35 \mathrm{mg} / 100 \mathrm{ml}$, midstream urine examination negative. Liver function tests normal. Serum protein levels: total $6 \cdot 5$, albumin $3 \cdot 2$, globulin $3.3 \mathrm{~g} / 100 \mathrm{ml}$. Serum vitamin $B_{12}$ levels on two separate occasions were 71 and $72 \mathrm{pg} / \mathrm{ml}$ respectively. Serum folate $16 \mathrm{ng} / \mathrm{ml}$. A bone marrow smear revealed megaloblastic erythropoiesis. A test meal showed the presence of free acid in the gastric juice. Faecal fat estimation on three successive occasions revealed normal values: $2 \cdot 7,1 \cdot 5$ and $3 \cdot 5$ 
$\mathrm{g} / 24 \mathrm{hr}$. Barium meal examination including followthrough normal. Schilling test normal. (Urinary excretion of ${ }^{57} \mathrm{Co}-$ labelled vitamin $\mathrm{B}_{12} 12 \%$ in 24 hr) CSF: normal pressure, no increase in cells, protein $40 \mathrm{mg} / 100 \mathrm{ml}$, no increase in globulin. WR negative. X-ray of chest normal. X-ray of cervical spine: a mild degree of degenerative arthritic changes, C5-6. Sternal marrow following vitamin $B_{12}$ therapy normal.

Treatment and course. She was treated with parenteral hydroxocobalamin because of her advanced neurological disease, $1000 \mu \mathrm{g}$ initially for 1 week, subsequently changed to $500 \mu \mathrm{g}$, twice a week and then once very 6 weeks. This we had to do because she was not sure whether she would revert to a normal diet. Her neurological disabilities improved considerably with this treatment. Within 3 weeks she was able to stand and walk with help, her plantar responses became flexor and her bone marrow and blood films became normal. Vibration sense however did not improve.

\section{Discussion}

Our patient was a vegan of 5 years' duration. She had clinical features of subacute combined degeneration of the spinal cord, there were some macrocytes in the blood film and a megaloblastic bone marrow. The presence of free acid in the gastric juice, the normal Schilling test and the absence of any evidence of malabsorption excluded both pernicious anaemia and idiopathic steatorrhoea. Bourne \& Oleesky (1960) suggested that to prove dietary vitamin $\mathrm{B}_{\mathbf{1 2}}$ deficiency as a cause of macrocytic anaemia it is necessary to have the following criteria: (1) a megaloblastic bone marrow, (2) normal vitamin $B_{12}$ absorption by one of the techniques using radio-active cyanocobalamin, (3) normal fat absorption, (4) the absence of complicating factors such as the taking of anticonvulsant drugs, pregnancy, or gastric operation, (5) a low serum level of vitamin $B_{12}$, (6) preferably the presence of free acid in the gastric juice, (7) conversion of the megaloblastic marrow to normoblastic by small oral doses of vitamin $B_{12}$. Our case fulfils all of these criteria, though the vitamin $B_{12}$ was not administered orally because of her advanced neurological disease.

There is no clear explanation why manifest neurological complications are rarer than haematological changes in such a deficiency state, though EEG abnormalities have often been noted in nutritional vitamin $\mathrm{B}_{12}$ deficiency states (Walton et al., 1954, West \& Ellis, 1966). Unfortunately we could not arrange an early EEG in our patient. Smith (1962) in his study of veganism pointed out that hydroxocobalamin is the most active analogue of vitamin $\mathbf{B}_{12}$. Cyanide in tobacco smoke is readily taken up by hydroxocobalamin to form cyanocobalamin, and cyanide has been incriminated as a toxic factor in producing nerve damage. The haematological deficit can be corrected by small doses of the cobalamin portion of the vitamin $\mathbf{B}_{12}$ molecule, whereas hydroxocobalamin is necessary to protect against neurological complications. Both the cases reported by Smith (1962) were smokers and the serum vitamin $B_{12}$ levels of the patients were 176 and $142 \mathrm{pg} / \mathrm{ml}$, levels which were considerably higher than those found in our patient ( 71 and $72 \mathrm{pg} / \mathrm{ml}$ ). Nevertheless, low levels of serum vitamin $\mathbf{B}_{\mathbf{1 2}}$ are not necessarily associated with symptoms and signs. Mehta, Rege \& Satoskar (1964) noted in a survey of healthy vegetarian medical students in India that more than half had a serum vitamin $B_{12}$ level of less than 100 $\mathrm{pg} / \mathrm{ml}$ without any symptoms and signs. This was again reported by Chanarin (1970). Smith (1962) believes that vegans, who are usually non-smokers and teetotallers, are protected from developing neurological complications because whatever limited quantity of vitamin $\mathbf{B}_{12}$ they possess is in hydroxocobalamin form.

We do not know for how long the very low serum level of vitamin $\mathbf{B}_{\mathbf{1 2}}$ had been present in our patient, and it may be that the chronic low level was one factor in the aetiology of her neurological disease. The high levels of folic acid normally found in vegan diets may also have contributed to the development of the neurological picture. But the role of chronicity in low serum levels of vitamin $B_{12}$, and that of the high levels of folate in the vegan diet in the genesis of neurological disease are not clear.

\section{Acknowledgment}

We are grateful to Dr C. D. R. Pengelly for his inspiration and guidance in the preparation of this case-report; and to Mrs H. P. Waites for secretarial help.

\section{References}

Badenoch, J. (1954) The use of labelled vitamin $\mathbf{B}_{12}$ and gastric biopsy in the investigation of anaemia. Proceedings of the Royal Society of Medicine, 47, 426.

Bourne, Martin S. \& Oleesky, Samuel (1960) Dietary deficiency of vitamin $\mathrm{B}_{12}$. British Medical Journal, 2, 511 .

Chanarin, P. (1970) Pernicious anaemia and other vitamin $\mathrm{B}_{12}$ deficiency states. Abstracts of World Medicine, 44, No. 2.

Connor, P.M. \& Pirola, R.C. (1963) Nutritional vitamin $\mathrm{B}_{12}$ deficiency. Medical Journal of Australia, 2, 451.

Mehta, B.M., Rege, D.V. \& Satoskar, R.S. (1964) Serum vitamin $B_{12}$ and folic acid activity in lacto-vegetarian and non-vegetarian healthy adult Indians. The American Journal of Clinical Nutrition, 15, 77.

RILEY, C.J. (1966) Unusual case of subacute combined degeneration of spinal cord. British Medical Journal, 2, 566.

Smirh, A.D. (1962) Veganism: A clinical survey with observations on vitamin $\mathrm{B}_{12}$ metabolism. British Medical Journal, 1, 1655. 
VerjaAl, A. \& Timmermans van den Bos, H.C.C. (1967) Combined degeneration of the spinal cord due to deficiency of alimentary vitamin $\mathbf{B}_{12}$. Journal of Neurology, NeuroSurgery and Psychiatry, 30, 464.

Walton, John N., KILOH, L.G., Osselton, J.W. \& Farrall, J. (1954) The electroencephalogram in pernicious anaemia and subacute combined degeneration of the cord. Electroencephalography and Clinical Neurophysiology, 6, 45.

WEST, E.D. \& ElLIS, F.R. (1966) The electroencephalogram in veganism, vegetarianism, vitamin $\mathbf{B}_{12}$ deficiency, and in controls. Journal of Neurology, Neuro-Surgery and Psychiatry, 29, 391.

Wokes, F., Badenoch, J. \& Sinclair, H.M. (1955) Human dietary deficiency of vitamin $\mathrm{B}_{12}$. American Journal of Clinical Nutrition, 3, 375.

WoKEs, F. (1956) Anaemia and vitamin $B_{12}$ dietary deficiency. Proceedings of the Nutrition Society, 15, 134.

\title{
Multiple unusual abnormalities in the electrocardiogram in myxoedema
}

\author{
J. DE SWIET \\ M.D., F.R.C.P. \\ Consultant Physician \\ East Glamorgan General Hospital, Glamorgan, Wales
}

DESCRIPTIONS of the electrocardiographic abnormalities in myxoedema have usually been confined to those of a sinus bradycardia, low-voltage QRS complexes, and T wave changes. Indeed, Wood (1968) described this combination as 'pathognomonic'. Additional changes, however, have been reported by other authors, including a prolonged Q-T interval (Hansen (1961), who also mentioned first degree heart-block), right bundle-branch block (Korth \& Schmidt, 1955), complete heart-block (Ibrahim, 1957) and supraventricular and ventricular paroxysmal tachycardia. A sinus tachycardia, slowing after specific treatment, and unexplained on any other grounds than myxoedema, does not appear to have been cited previously; while inverted $U$ waves also have not been described before in this disease.

\section{Case report}

A married woman of 53 was seen at out-patients with a 3-month history of fatigue, hoarseness, swollen hands, dry skin, puffy face, cramp in the feet, constipation, gain of a stone in weight, and recent cold intolerance. She had six children and had then been sterilized, but otherwise had an uneventful past history. Her menarche was at the age of $14 \frac{1}{2}$ and there was normal menstruation until the menopause at the age of 51. Particular questions were asked about possible anginal symptoms or other cardiac features, and none were elicited. There was no family history of any form of thyroid disease, diabetes mellitus, or pernicious anaemia, and no drugs had been taken in the remote or immediate past.

On examination her weight was $63 \mathrm{~kg}$, height 1.5 $\mathrm{m}$, temperature $35.5^{\circ} \mathrm{C}$, pulse-rate 88 , and blood- pressure $130 / 80 \mathrm{mmHg}$. She appeared normally alert, but had slightly puffy eyelids, a rough and dry skin over her arms, and there was no palpable thyroid tissue. The relaxation phase of her ankle-jerks was clearly prolonged. The clinical diagnostic index score was +41 (Billewicz et al., 1969).

Investigations included: serum electrolytes: $\mathrm{Na}$ $138, \mathrm{~K} \mathrm{4.0,Cl} \mathrm{101,} \mathrm{total} \mathrm{CO}_{2} 25 \mathrm{mEq} / 1$; plasmace calcium $10.6,10.6$ and $10.5 \mathrm{mg} / 100 \mathrm{ml}$; blood urea? $45 \mathrm{mg} / 100 \mathrm{ml}$; protein-bound iodine (PBI) 1.4 and $1.6 \mu \mathrm{g} / 100 \mathrm{ml}$; serum cholesterol $428 \mathrm{mg} / 100 \mathrm{ml}$; $\mathrm{Hb} 14.2 \mathrm{~g} / 100 \mathrm{ml}$; leucocytes $6,700 / \mathrm{mm}^{3}$ with normal differential count; urinalysis n.a.d.; negative autoprecipitin test for thyroid autoantibodies. Xray of chest showed no pulmonary or cardiac abnormality.

The electrocardiogram (Fig. 1) showed a sinus tachycardia (rate 120 in lead 1), left axis, semihorizontal position, normal voltage, widespread broadly-inverted $U$ waves, and a prolonged $\mathrm{Q}-\mathrm{T}$ interval $(0.36 \mathrm{sec}$, the average for the rate being $0.28 \mathrm{sec}$ corrected).

After 6 weeks treatment with thyroxine the electrocardiogram (Fig. 2) showed reduction of the sinus tachycardia to a rate of 100 , a more horizontal position, increased voltage of all complexes generally, absence of $U$ waves, and a normal Q-T interval. Normality of the ankle-jerks reflected a general clinical improvement in all respects, at the time of the repeat electrocardiogram.

\section{Discussion}

The clinical diagnosis of myxoedema appears certain in this case, but the pre-treatment electrocardiogram would suggest that this diagnosis was 